\title{
SPEKTRALNI POTPISI (ENDMEMBERI) NEKIH ŠUMSKIH VRSTA U REPUBLICI HRVATSKOJ
}

\section{SPECTRAL SIGNATURES (ENDMEMBERS) SOME OF FOREST SPECIES IN THE REPUBLIC OF CROATIA}

\author{
Mario ANČIĆ ${ }^{*}$, Renata PERNAR ${ }^{\text {, Milan BAJIĆ }}$, Andrija KRTALIĆ ${ }^{3}$, Ante SELETKOVIĆ1, \\ Dubravko GAJSKI ${ }^{3}$, Jelena KOLIĆ ${ }^{1}$
}

\section{SAŽETAK}

Svi objekti reflektiraju, apsorbiraju ili emitiraju elektromagnetsko zračenje ovisno o sastavu, stvarajući jedinstvene uzorke koje zovemo spektralni potpisi ili endmemberi. Čisti spektralni uzorci definiraju se u idealnim terenskim ili laboratorijskim uvjetima, gdje je spektar refleksije dobiven uporabom spektroradiometra fokusiranog na jednu površinu. Prema istraživanjima, većina spektralno čistih uzoraka odnosi se na istraživanja minerala. Spektralni potpisi vegetacije, za razliku od spektralnih potpisa minerala, su dinamični (u spektralnoj, prostornoj i vremenskoj rezoluciji), znatno zahtjevniji za prikupljanje i dokumentiranje, te ih treba s oprezom ugraditi u spektralne knjižnice. Postoji nekoliko spektralnih knjžnica (većih i manjih) koje su organizirane po poglavljima, a sastoje se od uzoraka koji imaju dovoljan broj analiza i dokumentaciju za utvrđivanje kvalitete spektra. U ovome istraživanju izdvojeni su spektralni potpisi za nekoliko vrsta u Hrvatskoj: hrast lužnjak (Quercus robur L.), običnu bukvu ( $F a-$ gus sylvatica L.), običnu jelu (Abies alba Mill.), običnu smreku (Picea abies L.), bijelu imelu (Viscum album L. ssp. Abietis (Weisb.)) i žutu imelu (Loranthus europaeus Jacq.). Svrha istraživanja je bila uspostaviti spektralnu knjižnicu za buduća istraživanja primjene hiperspektralnih skenera pri detekciji vrsta drveća.

Za prikupljanje spektralnih potpisa korišten je hiperspektralni linijski skener ImSpector V9, koji snima vidljivi i bliži infracrveni dio spektra od 430 do $900 \mathrm{~nm}$. Osim njega korišten je i senzor sunčevog zračenja FODIS, kako bi dobili prosječnu vrijednost sunčeve insolacije u trenutku snimanja. Snimanje je provedeno u kontroliranim uvjetima. Uzorci su postavljeni na kružnu podlogu sa naznačenom podjelom za svakih 45 stupnjeva točno u centru optičke osi skenera, te su rotirani kružno. Spektralne snimke su zatim obrađivane u softveru ImageJ gdje su izdvojeni podaci za daljnju analizu.

Nakon obračuna srednjih vrijednosti po vrstama napravljene su usporedbe između vrsta. Dobiveni rezultati pokazali su preklapanja u vidljivom dijelu spektra, dok u bližem infracrvenom dijelu spektra vrste diferenciraju jedna od druge, odnosno rezultati pokazuju kako postoji razlika između spektralnih krivulja uzoraka.

Provedenim istraživanjem definirani su postupci uzimanja uzoraka i dobiveni spektralni potpisi za istraživane vrste (endmemberi). Spektralni potpisi postali su dio spektralne knjižnice, a najznačajniji rezultat istraživanja je mogućnost primjene za detekciju vrsta na hiperspektralnim snimkama.

KLJUČNE RIJEČl: spektralni potpisi (endmemberi), hrast lužnjak, obična bukva, obična jela, obična smreka, bijela imela, žuta imela

\footnotetext{
${ }^{1}$ Doc. dr. sc. Mario Ančić, prof. dr. sc. Renata Pernar, izv. prof. dr. sc. Ante Seletković, dr. sc. Jelena Kolić, Zavod za izmjeru i uređivanje šuma, Šumarski fakultet Sveučilišta u Zagrebu, Svetošimunska 23, 10000 Zagreb, Hrvatska

*dopisni autor, e-adresa: mancic@sumfak.hr

${ }_{2}^{2}$ Prof. dr. sc. Milan Bajić umirovljeni profesor, Geodetski fakultet Sveučilišta u Zgrebu, Kačićeva 26, 10000 Zagreb, Hrvatska

${ }^{3}$ Doc. dr. sc. Andrija Krtalić, doc. dr. sc. Dubravko Gajski, Geodetski fakultet Sveučilišta u Zagrebu, Kačićeva 26, 10000 Zagreb, Hrvatska
} 


\section{UVOD}

Hiperspektralni senzori preletom preko nekog područja skeniraju tlo i skupljaju svjetlosne „potpise“ (čiste spektralne uzorke, endmembere) biljaka, minerala i svih ostalih objekata (Rajendran, S. i dr. 2009, Santonu G. i Kuldeep M. 2015). Na hiperspektralnim snimkama apsorpcija i raspršivanje čestica formira karakteristične potpise i na taj način omogućava detekciju objekata (Buckingham i dr. 2002).

Svi objekti reflektiraju, apsorbiraju ili emitiraju elektromagnetsko zračenje (svjetlost) ovisno o njihovom sastavu, stvarajući na taj način jedinstveni uzorak zvan „spektralni potpis“ (Rajendran, S. i dr. 2009, Santonu G. i Kuldeep M. 2015).

Čistim spektralnim uzorcima smatramo najekstremnije ili spektralno „čiste“ elemente (npr. jela, dolomit, i dr.). Oni se najčešće definiraju u idealnim terenskim ili laboratorijskim uvjetima, gdje je spektar refleksije dobiven uporabom prijenosnog spektroradiometra fokusiranog na jednu površinu (npr. na jedan list na stablu). U slučaju kada nije moguće terensko mjerenje, endmemberi se mogu izdvojiti iz čistih elemenata snimke (Piwowar 1999), uz pretpostavku kako se na snimljenoj sceni nekog područja nalaze takvi čisti spektralni uzorci, te da je prostorna rezolucija u takvom slučaju dovoljno velika $(<1 \mathrm{~m})$, jer se u tom slučaju povećava mogućnost odabira spektralno čistog uzorka (Ticehurst i dr. 2001, Culvenor 2002, Held i dr. 2003).

Većina spektralno čistih uzoraka odnosi se na geološka istraživanja minerala, dok su spektralni potpisi vegetacije dinamični u spektralnoj, prostornoj i vremenskoj dimenziji, te bi ih s oprezom trebalo ugraditi u spektralne knjižnice (Elvidge 1990, Salisbury i dr. 1991, Grove i dr. 1992, Clark i dr. 1993, Salisbury i dr. 1994, Korb i dr. 1996, Asner i Heiderbrecht 2002, Shippert 2003, Lucas i dr. 2004).

Spektralna geometrija potpisa vegetacije varira u skladu s biokemijskim sadržajem i fizičkom strukturom biljnog tkiva i daljnjim utjecajem fenoloških, prirodnih i antropogeno izazvanih čimbenika. Poznavanje uzroka variranja od temeljne je važnosti za razumijevanje informacijskih sadržaja spektra dobivenih mjerenjem na terenu, laboratoriju ili izravnim očitavanjem sa zrakoplovnih ili svemirskih snimaka (Lucas i dr. 2004).

Postoji nekoliko knjižnica čistih spektralnih potpisa, dvije velike knjižnice: USGS, (Clark i dr. 2007, Kokaly i dr. 2017) i ASTER (Baldridge i dr. 2009), te nekoliko manjih spektralnih knjižnica (Christensen i dr. 2000), a organizirane su po poglavljima (tablica 1).

Idealna spektralna knjižnica sastoji se od uzoraka koji pokrivaju širok raspon materijala, ima velik opseg valnih duljina, dovoljno analiza uzoraka i dokumentaciju za utvrđivanje kvalitete spektra (Clark i dr. 2007, Kokaly i dr. 2017).

Uzorci vegetacije i vegetacijom obrasla područja znatno su zahtjevniji u prikupljanju podataka i dokumentiranju. Osnovna dokumentacija zahtijeva datum uzimanja uzorka i točnu identifikaciju vrste. Poželjna je dodatna dokumentacija o koncentraciji vode i pigmenata u listu, što zahtijeva povezivanje $s$ laboratorijskim analizama tih uzoraka. $\mathrm{Za}$ terenska mjerenja vegetacijom obraslih područja (vegetacijske zajednice) potrebno je evidentirati vrste mjerenog područja i postotni udio pokrivanja površine po svakoj vrsti (Clark i dr. 2007).

Ključni opisni elementi spektralnih potpisa vegetacije uključuju značajke poput „Green peak“ (zeleni vrh), „Chlorpohyll well“ (klorofilni zdenac), „Red edge“ (crveni rub) i „NIR plateau“ (slika 1) (Kumar 1998, Huber i dr. 2005). Od posebnog značaja je „Red edge“, koji je definiran kao porast refleksije na granici između apsorpcije klorofila u crvenom dijelu i raspršivanja unutar lista u području bližeg infracrvenog dijela spektra (Treitz i Howarth 1999). Red edge prikazuje najveću promjenu refleksije s obzirom na promjenu spektralnih značajki, bilo kojeg zelenog lista u VNIR području (Elvidge i dr. 1990), a obično se identificira pomoću točke infleksije crvenog ruba (REIP - Red-Edge Inflection Point) ili točkom maksimalnog nagiba, a nalazi se između 680 i 750 nm, bez obzira na vrstu (Kumar i dr. 2001).

Prva hiperspektralna istraživanja u Hrvatskoj započela su u okviru programa Europske zajednice, u sklopu dva međunarodna projekta (ARC 1998.-2002. i SMART 2001.2004.) financiranih od strane Europske komisije, vezanim za smanjivanje minsko sumnjivih površina u Hrvatskoj. $\mathrm{Na}$

Tablica 1. Izgled USGS spektralne knjižnice organizirane prema poglavljima (Clark i dr. 2007)

Table 1. Layout of the USGS Spectral Library organized by Chapters (Clark et al.)

$\begin{array}{ccl}\text { Poglavlje } & \text { Oznaka } & \\ 1 & \text { M } & \text { Minerals (minerali) } \\ 2 & \text { S } & \text { Soils, Rocks and Mixtures (tla, stijene i mješavine (isključene su mješavine s vegetacijom)) } \\ 3 & \text { C } & \begin{array}{l}\text { Coatings (pokrov) } \\ \text { Liquids, Liquid Mixtures, Water, Other Volatiles and Frozen Volatiles (tekućine, mješavine tekućina, voda, druge hlapljive tekućine }\end{array} \\ 4 & \text { L } & \begin{array}{l}\text { Li smrznute tekućine) } \\ \text { i }\end{array} \\ \text { A } & \text { A } & \begin{array}{l}\text { Artificial (Man Made) Including Manufactured Chemicals (umjetni materijali koje je napravio čovjek uključujući proizvedene } \\ \text { kemikalije) }\end{array} \\ 6 & \text { V } & \begin{array}{l}\text { Plants, Vegetation Communities, Mixtures with Vegetation and Microorganisms (biljke, biljne zajednice, mješavine s vegetacijom } \\ \text { i mikroorganizmi) }\end{array}\end{array}$




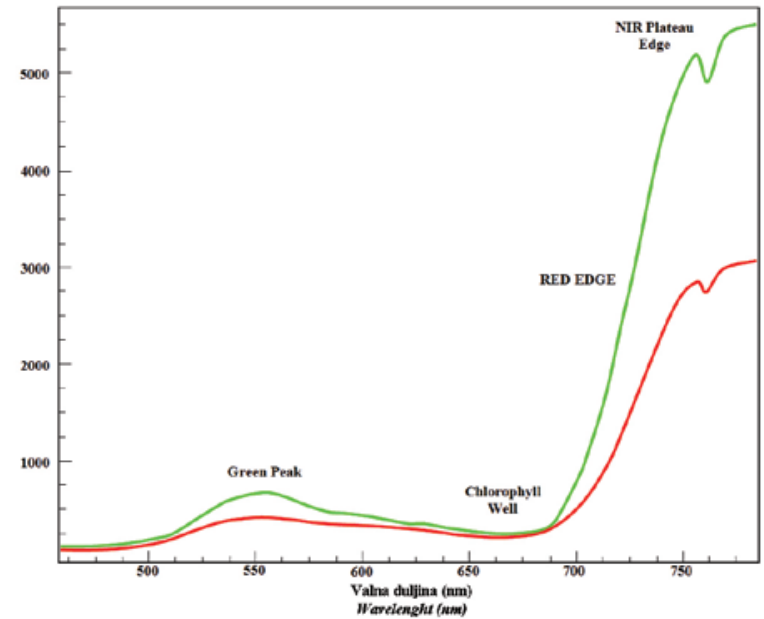

Slika 1. Prikaz pojmova Green peak, Chlorophyll Well, Red edge i NIR Plateau Edge na spektralnoj krivulji (http://www.geoplace.com/Media/ PublicationsArticle/Figure-4_3.jpg)

Figure 1. Display of Green peak, Chlorophyll Well, Red edge and NIR Plateau Edge on a spectral curve (http://www.geoplace.com/Media/PublicationsArticle/Figure-4_3.jpg)

temelju iskustava i rezultata navedenih istraživanja, na Medvednici je bilo provedeno, multispektralno i hiperspektralno snimanje linijskim hiperspektralnim skenerom ImSpector V9. Kao rezultat su dobivene prve spektralne krivulje refleksije jele i imele (Pernar i dr. 2005, Pernar i dr. 2007), koje su poslužile kao ulazni parametri za istraživanja na području UŠP Gospić u svrhu ispitivanja mogućnosti detekcije oštećenosti jele s posebnim osvrtom na otkrivanje imele na jeli.

Na osnovi rezultata provedenih istraživanja i uspješnog razdvajanja spektara jele i imele (Ančići i dr. 2014) prema istim procedurama izdvojeni su spektralni potpisi za slijedeće vrste u Hrvatskoj: hrast lužnjak (Quercus robur L.), običnu bukvu (Fagus sylvatica L.), običnu smreku (Picea abies L.) i žutu imelu (Loranthus europaeus Jacq.).

Svrha provedenih istraživanja bila je uspostaviti spektralnu knjižnicu za buduće primjene hiperspektralnih skenera pri detekciji vrsta drveća i zaraze imelom.

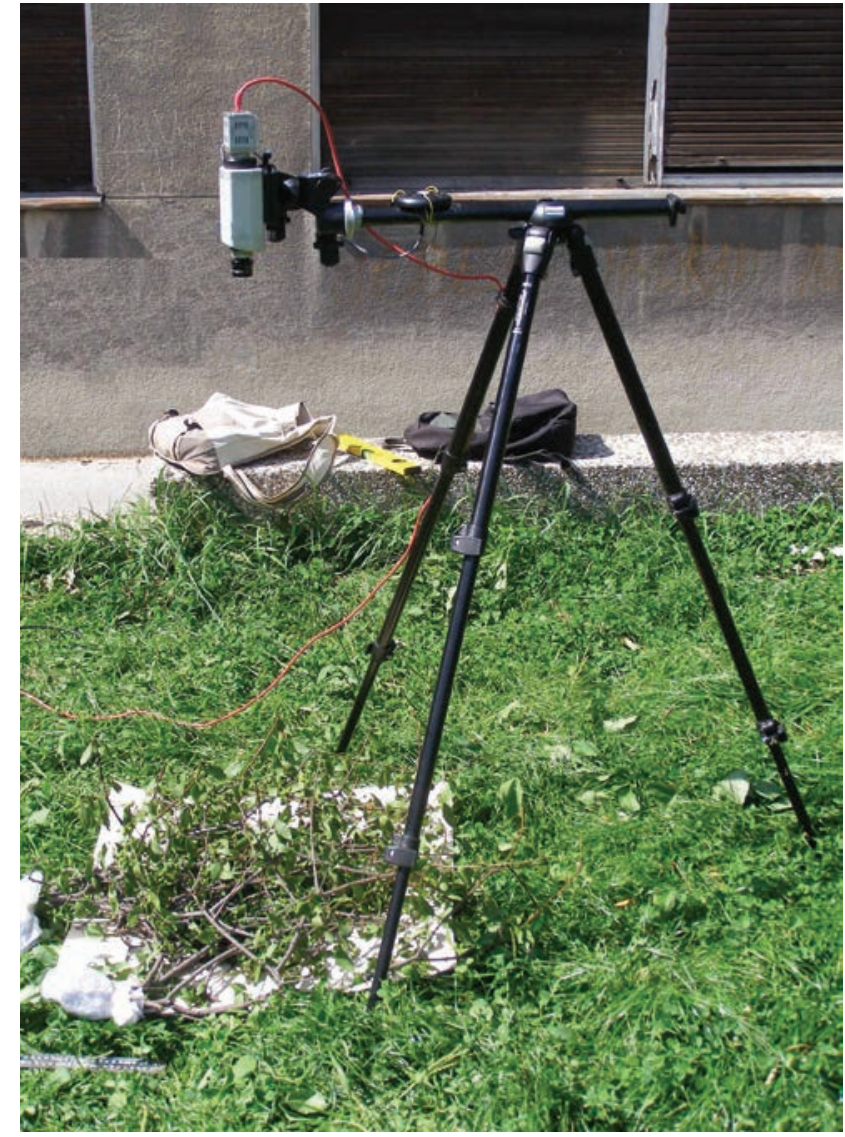

Slika 2. Snimanje hiperspektralnim linijskim skenerom ImSpector V9 (Ančić 2011)

Figure 2. Recording with Hyperspectral Line Scanner ImSpector V9 (Ančić 2011)

\section{MATERIJALI I METODE}

Snimanje uzoraka provedeno je hiperspektralnim linijskim skenerom ImSpector V9 spektralnog opsega 430-900nm i PCO PixelFly monokromatskim senzorom (24 slike/sekundi, rezolucije $640 \times 512 / 8$ bita ili 1280x1024/12 bita piksela (Miljković i dr. 2017). Hiperspektralni skener postavljen je zajedno sa senzorom svjetlosnog zračenja - FODIS (Fiber Optic Downwelling Irradiance Sensor) na visinu jednoga metra iznad tla (slika 2.). Dužina linije snimanja je

Tablica 2. Vrijeme snimanja i broj snimaka po vrstama i ukupno (Ančić 2011).

Table 2. Time and number of recordings by species and total (Ančić 2011).

\begin{tabular}{|c|c|c|c|}
\hline $\begin{array}{l}\text { Vrsta } \\
\text { Species }\end{array}$ & $\begin{array}{l}\text { Početak snimanja } \\
\text { Start recording } \\
\text { (h) }\end{array}$ & $\begin{array}{l}\text { Kraj snimanja } \\
\text { End of recording } \\
\text { (h) }\end{array}$ & $\begin{array}{l}\text { Broj snimaka po vrsti } \\
\text { Number of records per } \\
\text { species }\end{array}$ \\
\hline obična jela (Abies alba Mill. ) & $13: 38$ & $13: 43$ & 203 \\
\hline obična smreka (Picea abies /L./Karsten) & $13: 49$ & $13: 56$ & 199 \\
\hline hrast lužnjak (Quercus robur L.) & $12: 11$ & $12: 16$ & 192 \\
\hline obična bukva (Fagus sylvatica L.) & $12: 59$ & 13:05 & 189 \\
\hline žuta imela (Loranthus europaeus Jacq.) & $12: 00$ & $12: 07$ & 224 \\
\hline \multirow[t]{2}{*}{ bijela imela (Viscum album ssp. abietis Niesb./Abrom.) } & $12: 20$ & $12: 26$ & 201 \\
\hline & & Ukupan broj snimaka & 1208 \\
\hline
\end{tabular}




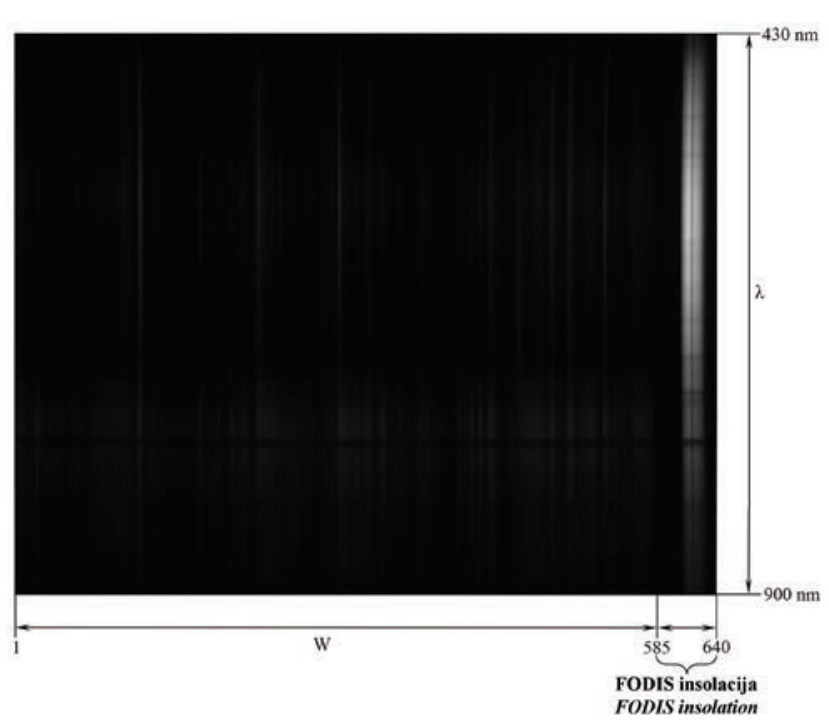

Slika 3. Prikaz snimljene 8-bitne datoteke (Ančić 2011)

Figure 3. Display of the recorded 8-bit file (Ančić 2011)

iznosila 33,3\%, a širina linije iznosi 0,208\% visine, odnosno $0,333 \mathrm{~m} \times 0,00208 \mathrm{~m}$ (Šemanjski i dr. 2009).

Uzorci su postavljani ispod skenera, u središte optičke osi, na podlogu pričvršćenu na tlo, sa označenom podjelom punog kruga za svakih $45^{\circ}$. Snimanje je započelo u 12:00 i trajalo je do 13:56 sati (tablica 2.). Ukupno je snimljeno 1208 snimaka.

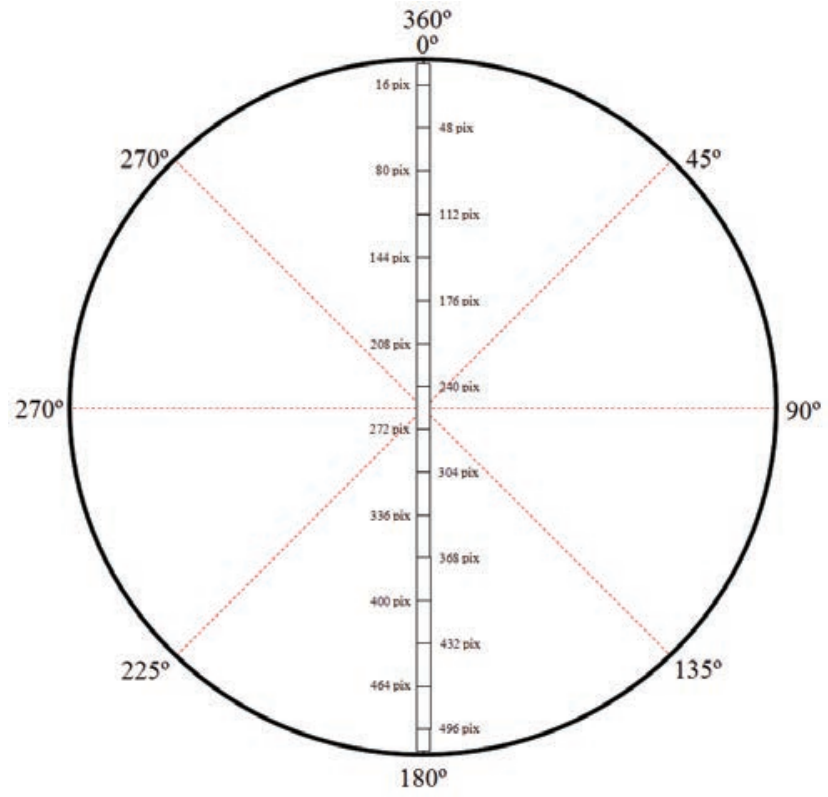

Slika 4. Shematski primjer uzorkovanja u linijama za odabrane piksele za svakih $45^{\circ}$ (Ančić 2011).

Figure 4. Schematic representation of sampling in lines for selected pixels for every $45^{\circ}$ (Ančić 2011).

Snimljeni podaci sadrže jednu ${ }^{\star} . x l s$ datoteku (broj snimljenih linija, datum i vrijeme snimanja, dužina ekspozicije, i dr.) i niz ${ }^{*}$.tif 8 bitnih snimki u sivim tonovima (slika 3.).

Tablica 3. Dio tablice za običnu jelu (Abies alba Mill.) na 16. pikselu za 0 stupnjeva (Ančić 2011).

Table 3. Part of a table for silver fir (Abies alba Mill.) on 16th pixel for 0 degrees (Ančić 2011).

\begin{tabular}{|c|c|c|c|c|c|c|c|}
\hline \multicolumn{8}{|c|}{ 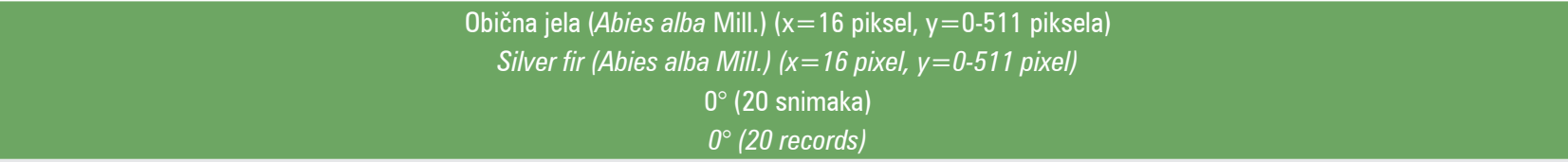 } \\
\hline $\begin{array}{l}\text { Piksel } \\
\text { Pixel }\end{array}$ & $\begin{array}{c}\text { Valne duljine } \\
\text { Wavelength }(\mathrm{nm})\end{array}$ & $\begin{array}{l}\text { Reflekt. očitanje } \\
\text { Reflected reading }\end{array}$ & $\begin{array}{l}\text { Reflekt. arit. sred. } \\
\text { Reflected arith. } \\
\text { mean }\end{array}$ & $\begin{array}{l}\text { FODIS očitanje } \\
\text { FODIS reading }\end{array}$ & $\begin{array}{l}\text { FODIS arit. sred. } \\
\text { FODIS arith. mean }\end{array}$ & $\begin{array}{l}\text { Koef. refleksije } \\
\text { Reflection coeff. }\end{array}$ & $\begin{array}{c}\text { Koef. refleksije } \\
\text { Reflection coeff. } \\
(\%)\end{array}$ \\
\hline 1 & 430,00 & 22,00 & 1,10 & 546,00 & 27,30 & 0,0403 & 4,0293 \\
\hline 2 & 430,92 & 24,00 & 1,20 & 564,00 & 28,20 & 0,0426 & 4,2553 \\
\hline 3 & 431,84 & 25,00 & 1,25 & 582,00 & 29,10 & 0,0430 & 4,2955 \\
\hline 4 & 432,76 & 21,00 & 1,05 & 601,00 & 30,05 & 0,0349 & 3,4942 \\
\hline$n$ & $\ldots$ & $\ldots$ & ... & $\ldots$ & $\ldots$ & $\ldots$ & $\ldots$ \\
\hline
\end{tabular}

Tablica 4. Dio tablice za običnu jelu (Abies alba Mill.) s podacima izdvojenim po svim pikselima samo za $0^{\circ}$ (Ančić 2011).

Table 4. Part of a table for silver fir (Abies alba Mill.) with data extracted on all processed pixels only at $0^{\circ}$ (Ančić 2011).

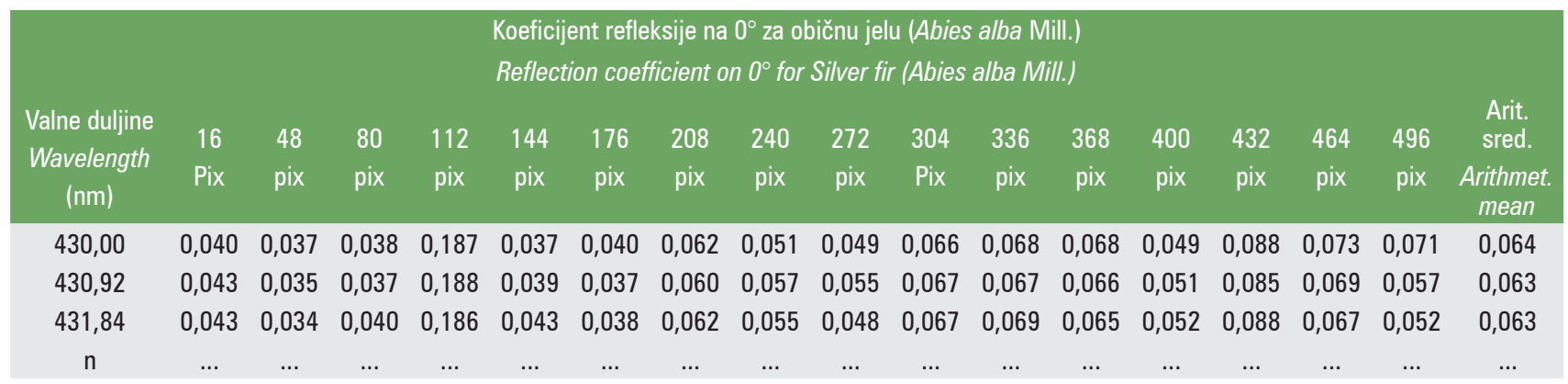




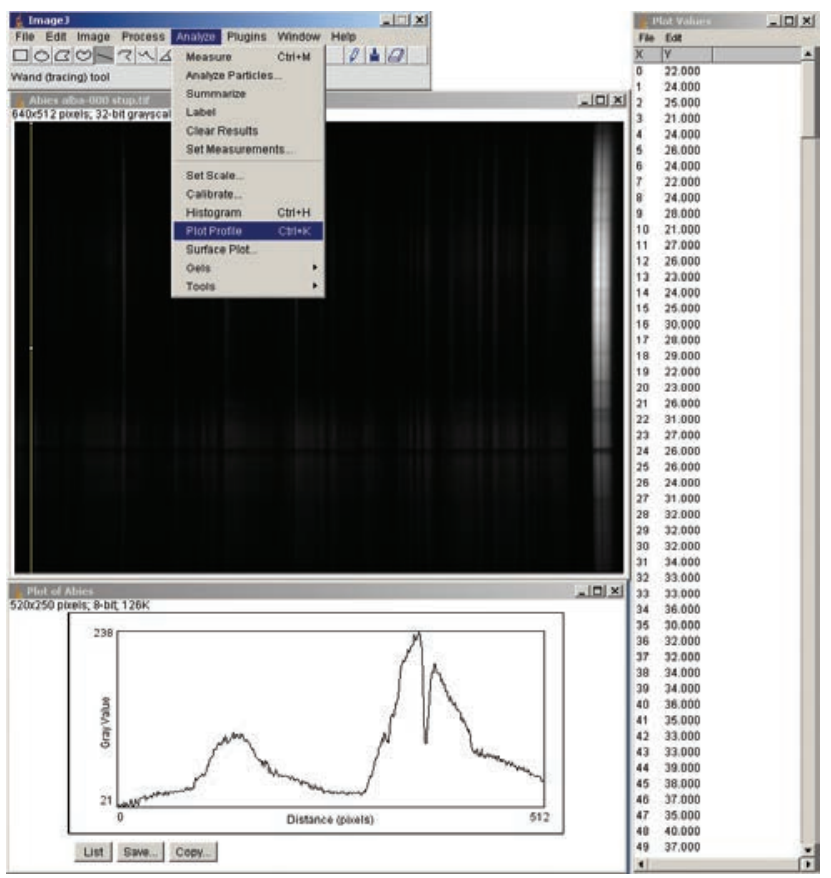

Slika 5. Postupak očitavanja spektralnih vrijednosti (izdvojene su vrijednosti za 16. piksel), grafički prikaz i podatci u tekstualnom obliku (Ančić 2011).

Figure 5. The procedure of reading spectral values (extracted values for 16 pixel ), graphical representation and data in text format (Ančić 2011).

Snimljeni podaci vezani uz vrstu i kut (slika 4) učitani su u program ImageJ, pomoću kojega su potom izdvajane spektralne vrijednosti (spektralni profili i brojčane vrijednosti) po odabranim pikselima za vrstu i odabrani stupanj unutar vrste. (slika 5) za daljnju obradu.

Za svaki stupanj po odabranim pikselima na snimljenim uzorcima (tablica 3) dobiveni su koeficijenti refleksije (decimalne i postotne vrijednosti) po valnim duljinama (slika 6)

Nakon izdvajanja koeficijenata refleksije po vrstama, za sve piksele unutar jednoga stupnja napravljena je nova tablica sa grupiranim podacima za vrijednosti očitanih piksela po stupnjevima (tablica 4). U toj tablici su izračunate aritmetičke vrijednosti svih piksela unutar jednoga stupnja koji će se koristiti u daljnjoj obradi.

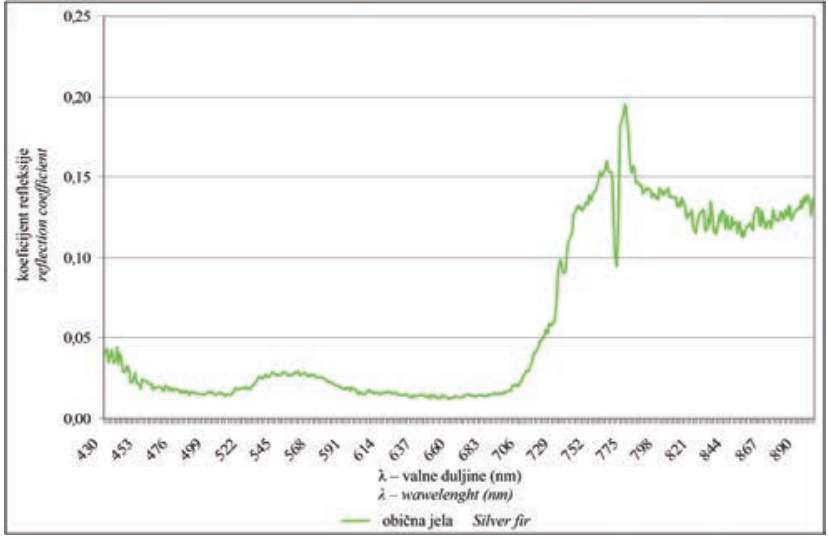

Slika 6. Vrijednost koeficijenta refleksije za uzorak obične jele (Abies alba Mill.) 16. piksel na $0^{\circ}$ (Ančić 2011).

Figure 6. The reflection coefficient value for a sample of silver fir (Abies alba Mill.) 16th pixel at $0^{\circ}$ (Ančić 2011).

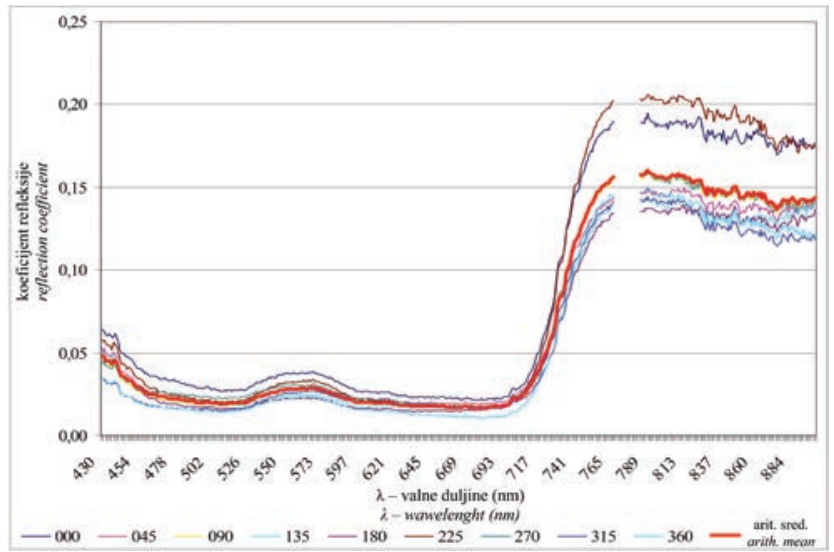

Slika 7. Aritmetičke sredine koeficijenata refleksija za običnu jelu (Abies alba Mill.) po stupnjevima i njihova prosječna vrijednost (Ančić 2011). Figure 7. Arithmetic means of the reflection coefficients for silver fir (Abies alba Mill.) by degrees and their average value (Ančić 2011).

Nakon izdvajanja, izračunate su srednje vrijednosti aritmetičkih sredina po stupnjevima (zasebno za svaku vrstu) (tablica 5, slika 7)

U tablicama su isključeni dijelovi spektra od 766 do $784 \mathrm{~nm}$ (slika 7), zbog utjecaja apsorpcijskog maksimuma (apsor-

Tablica 5. Dio tablice za običnu jelu (Abies alba Mill.) sa srednjim vrijednostima aritmetičkih sredina koeficijenta refleksije izdvojenim po stupnjevima (Ančić 2011).

Table 5. Part of a table for silver fir (Abies alba Mill.) with the average values of the arithmetic means of the reflection coefficients separated by degrees (Ančić 2011).

\begin{tabular}{|c|c|c|c|c|c|c|c|c|c|c|}
\hline \multicolumn{11}{|c|}{$\begin{array}{l}\text { Aritmeticke sredine koeficijenta refleksije po stupnjevima za običnu jelu (Abies alba Mill.) } \\
\text { Arithmetic mean of the reflection coefficient by degrees for a Silver fir (Abies alba Mill.) }\end{array}$} \\
\hline $\begin{array}{c}\text { Valne duljine } \\
\text { Wavelength } \\
\quad(\mathrm{nm})\end{array}$ & $0^{\circ}$ & $45^{\circ}$ & $90^{\circ}$ & $135^{\circ}$ & $180^{\circ}$ & $225^{\circ}$ & $270^{\circ}$ & $315^{\circ}$ & $360^{\circ}$ & $\begin{array}{l}\text { Arit. sred. } \\
\text { Arithmet. mean }\end{array}$ \\
\hline 430,00 & 0,064 & 0,053 & 0,045 & 0,050 & 0,049 & 0,057 & 0,044 & 0,035 & 0,036 & 0,048 \\
\hline 430,92 & 0,063 & 0,051 & 0,045 & 0,050 & 0,047 & 0,057 & 0,045 & 0,034 & 0,035 & 0,047 \\
\hline 431,84 & 0,063 & 0,052 & 0,044 & 0,048 & 0,047 & 0,058 & 0,043 & 0,034 & 0,034 & 0,047 \\
\hline $\mathrm{N}$ & $\ldots$ & $\ldots$ & $\ldots$ & $\ldots$ & $\ldots$ & $\ldots$ & $\ldots$ & $\ldots$ & $\ldots$ & $\ldots$ \\
\hline
\end{tabular}




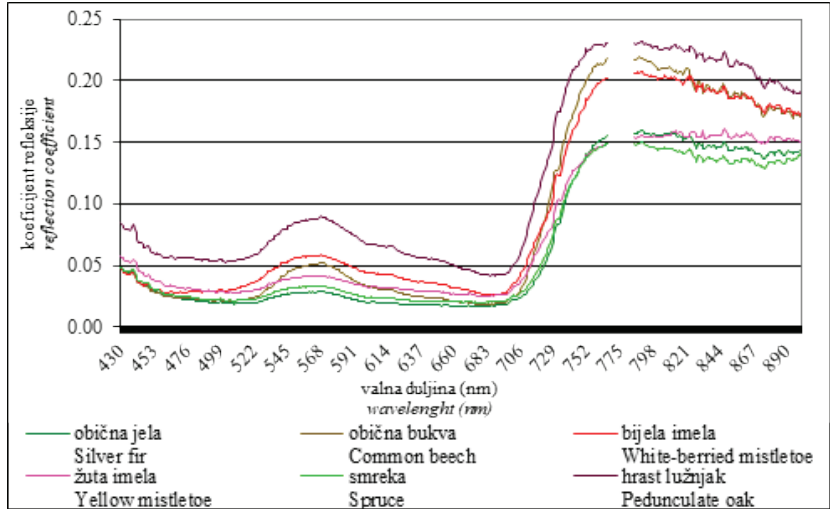

Slika 8. Grafički prikaz aritmetičkih sredina za sve snimane vrste. Figure 8. Chart of arithmetic means for all recorded species.

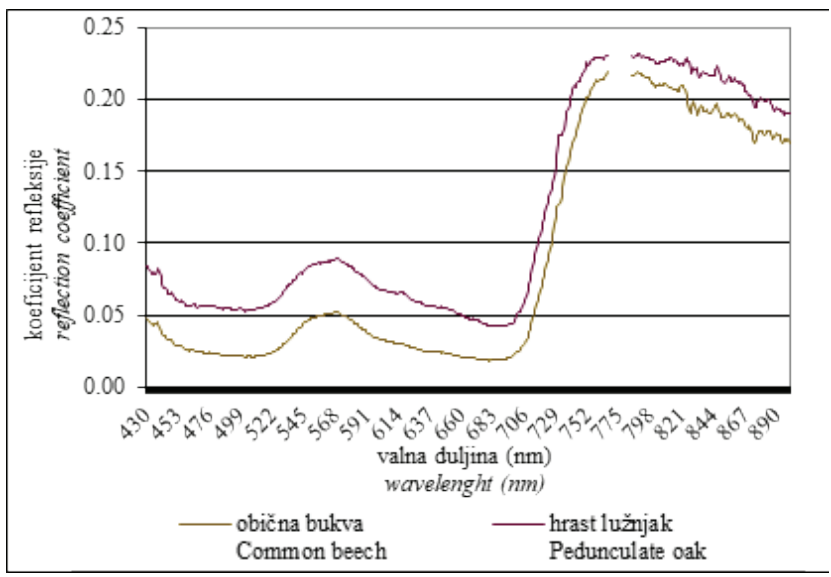

Slika 9. Usporedba spektralnih krivulja za hrast lužnjak i običnu bukvu. Figure 9. Comparison of spectral curves for Oak and Common beech.

pcija elektromagnetskog zračenja koju uzrokuje vodena para u zraku, a izaziva nagle padove i skokove $\mathrm{u}$ dijelovima spektralnog profila) (slika 6).

Uspoređene su spektralne krivulje prema šumskim staništima i prema tome koja je biljka domaćin kojoj od poluparazitskih biljaka. Osim usporedbom spektralnih krivulja, diferenciranje je potvrđeno i $t$-testom. Na taj način uspoređene su:

- spektralne krivulje hrasta lužnjaka i obične bukve (šume listopadnih hrastova izvan dohvata poplava (Carpino betuli-Quercetum roboris fagetosum Rauš 1973 (Vukelići dr. 2008));

- spektralne krivulje hrasta lužnjaka i poluparazitske žute imele na hrastu (Idžojtić i dr. 2005, Idžojtić i dr. 2006a, Idžojtić i dr. 2006b, Idžojtić i dr. 2007, Idžojtić i dr. 2009);

- spektralne krivulje obične jele, obične bukve i obične smreke (bukovo jelove šume, pretplaninske bukovim šume i kontinentalne crnogorične šume (Vukelić i dr. 2008));
- spektralne krivulje obične jele i poluparazitske bijele imele na jeli (Idžojtić i dr. 2003, Idžojtić i dr. 2006a, Idžojtić i dr. 2006b, Idžojtić i dr. 2007);

- spektralne krivulje poluparazitskih vrsta bijele i žute imele.

\section{REZULTATI I DISKUSIJA}

Dobiveni rezultati potvrđuju mogućnost razdvajanja spektralnih krivulja (slika 8), ali ujedno i ukazuju na preklapanje u pojedinim dijelovima spektra za pojedine vrste, što je bilo i očekivano.

Uspoređene spektralne krivulje hrasta lužnjaka i obične bukve pokazuju jasnu diferencijaciju duž cijeloga spektra od 430 do $900 \mathrm{~nm}$, što dokazuje i rezultat $t$-testa $\mathrm{p}<0,001$ (slika 9). Na grafičkom prikazu vidljivo je kako hrast lužnjak i obična bukva dobro diferenciraju u vidljivom i infracrvenom dijelu spektra.

Usporedbom spektralnih krivulja hrasta lužnjaka i žute imele koja dolazi na hrastu lužnjaku, vidimo jasno razliko-

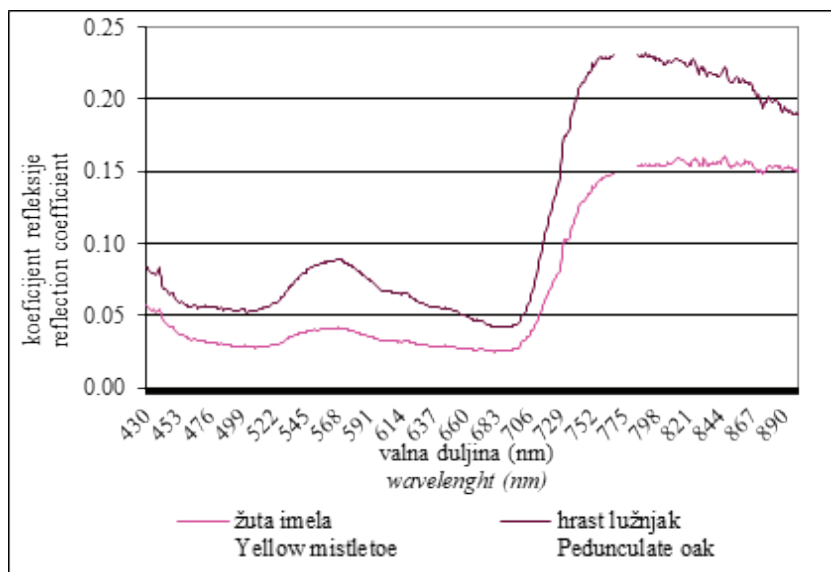

Slika 10. Spektralne krivulje hrasta lužnjaka i žute imele.

Figure 10. Spectral curves for Oak and Yellow mistletoe.

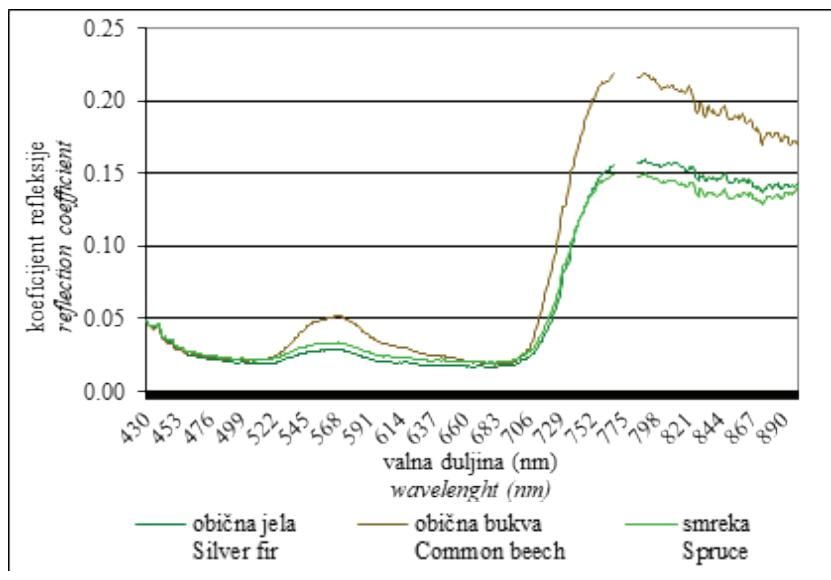

Slika 11. Spektralne krivulje obične jele, obične bukve i obične smreke. Figure 11. Spectral curves for Silver fir, Common beech and Spruce. 


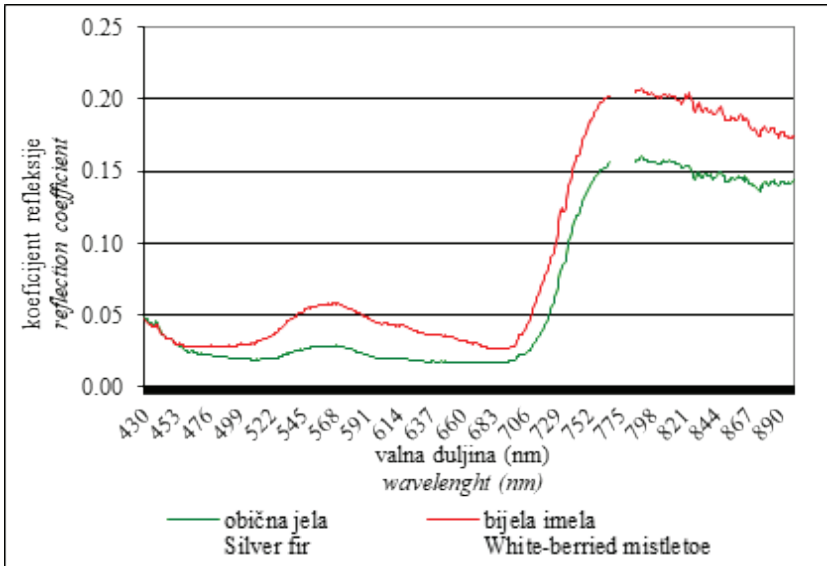

Slika 12. Spektralne krivulje obične jele i bijele imele (Ančić 2011) Figure 12. Spectral curves for Silver fir and White-berried mistletoe (Ančić 2011).

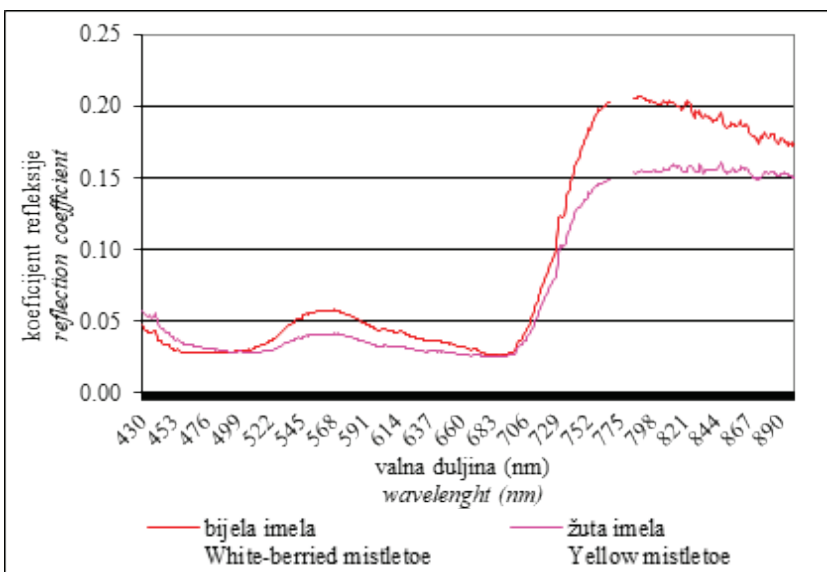

Slika 13. Spektralne krivulje poluparazitskih vrsta bijele i žute imele Figure 13. Spectral curves for White-berried mistletoe and Yellow mistletoe.

vanje njihovih spektralnih krivulja ( $t$-test $\mathrm{p}<0,001)$, što ukazuje na mogućnost detekcije zaraženosti hrasta lužnjaka imelom (slika 10).

Nakon usporedbe spektralnih krivulja obične jele, obične bukve i obične smreke (slika 11), vidljivo je kako se obična jela i obična smreka slabo diferenciraju u vidljivom dijelu ( $t$-test $\mathrm{p}=0,917)$, za razliku od obične bukve, čija je spektralna refleksija znatno veća u području red edge prema bližem infracrvenom području, $(t$-test $\mathrm{p}<0,001)$ i $t$-test za običnu smreku i običnu bukvu ( $t$-test $\mathrm{p}<0,001)$.

Usporedbom spektralnih krivulja obične jele i bijele imele (slika 12), možemo potvrditi njihovo jasno diferenciranje, što dokazuje uspješnost primjene u detekciji imele na hiperspektralnim snimkama.

Pregledom spektralnih krivulja bijele i žute imele (slika 13.), te njihovom usporedbom možemo utvrditi da se u vidljivom dijelu spektra obje vrste mogu teško razlikovati, dok se u području od 700 do $900 \mathrm{~nm}$ njihove krivulje jasno raz- dvajaju, što upućuje na mogućnost prepoznavanja i detekcije na snimkama $(t$-test $\mathrm{p}<0,001)$.

Rezultati istraživanja proučavanih glavnih šumskih vrsta u Hrvatskoj i dvije vrste imela većinom su pokazali malu diferencijaciju spektralih krivulja u vidljivom dijelu spektra, dok u bližem infracrvenom navedene vrste jasno diferenciraju, odnosno moguća je detekcija tih vrsta na hiperspektralnim snimkama. Isto je potvrđeno i $t$-testom, koji je pokazao statistički značajne razlike između svih spektralnih krivulja, osim između spektralnih krivulja obične jele i obične smreke.

Takvo razdvajanje spektralnih krivulja olakšava njihovu determinaciju, kao i mogućnost razlikovanja jedne vrste (poluparazit bijela imela) unutar krošnje druge vrste (obična jela) (Ančić 2011, Ančić i dr. 2014). Budući da su provedenim istraživanjem potvrđene prednosti hiperspektralnih snimaka u detekciji vrsta drveća i zaraženosti pojedinih vrsta imelom, za preporučiti je operativnu primjenu ovih metoda u šumarstvu.

U prilog tome idu istraživanja Diminića i dr. (2011), kojima su zaključili da terestrička analiza prisutnosti imele u krošnji dubećeg stabla nije pouzdana. S jedne strane neuočljivost imele ne znači da analizirano stablo nije zaraženo imelom, jer grmovi mogu biti zaklonjeni granama, a s druge strane, stvarni broj grmova imele uopće nije moguće evidentirati zbog nemogućnosti detaljnog pregleda svake pojedine grane s tla. Jedina pouzdana metoda koja će nam dati stvarni uvid u zaraženost pojedine vrste drveća imelom, jest analiza na oborenim stablima. Nadalje naglašavaju da bi buduća istraživanja praćenja zaraze imelom trebalo usmjeriti na daljinska istraživanja, radi izbjegavanja obaranja većeg broja stabala i zahtjevnijih terenskih radova.

\section{ZAKLJUČAK}

$\mathrm{Na}$ osnovi provedenih snimanja pojedinih vrsta drveća i dvije poluparazitske vrste, hiperspektralnim linijskim skenerom ImSpector V9 možemo donijeti sljedeće zaključke: provedenim istraživanjem definirani su postupci uzimanja uzoraka za određivanje endmembera i kreiranje spektralnih knjižnica;

određeni su čisti spektralni uzorci (endmemberi) za neke od najvrijednijih komercijanih vrsta u Republici Hrvatskoj (hrast lužnjak, obična bukva, obična jela i obična smreka), te za dvije poluparazitske vrste (bijela i žuta imela);

spektralni potpisi navedenih uzoraka su dio spektalne knjižnice, te mogu poslužiti u budućim hiperspektralnim istraživanjima za detekciju vrsta drveća i zaraze imelom kako za potrebe šumarstva (zaštite šuma, uređivanja, iskorištavanja šuma) tako i za potrebe drugih znanstvenih disciplina. 


\section{LITERATURA}

- Ančić, M. 2011: Primjena multispektralnih i hiperspektralnih snimaka u procjeni oštećenosti obične jele (Abies alba Mill) i detekciji imele (Viscum album L. ssp. abietis (Wiesb.) Abrom.). Doktorska disertacija. Šumarski fakultet Zagreb.

- Ančić, M., R. Pernar, M. Bajić, A. Seletković, J. Kolić, 2014: Detecting mistletoe infestation on Silver fir using hyperspectral images, iForest - biogeosciences and forestry, 7: 85-91

- Asner, G. P., K. B. Heiderbrecht, 2002: Spectral unmixing of vegetation, soil and dry carbon cover in arid regions: comparing multispectral and hyperspectral observations. International Journal of Remote Sensing 23(19): 3939-3958.

- Baldridge, A. M., S. J. Hook, C. I. Grove, G. Rivera, 2009: The ASTER spectral library version 2.0. Remote Sensing of Environment 113: 711-715 str.

- Buckingham, B., K. Staenz, A. Hollinger, 2002: Review of Canadian airborne and space activities in hyperspectral remote sensing. Canadian Aeronautics and Space Journal 48(1): 115121 str.

- Christensen, P. R., J. L. Bandfield, V. E. Hamilton, D. A. Howard, M. D. Lane, J. L. Piatek, S. W. Ruff, W. L. Stefanow, 2000: A thermal emission spectral library of rock-forming minerals. Journal of Geophysical Research-Planets 105(E4): 9735-9739 str.

- Clark, R. N., G. A. Swayze, A. J. Gallagher, T. V.V. King, W. M. Calvin, 1993: The U. S. Geological Survey, Digital Spectral Library. Version 1: 0.2 to 3.0 microns. U.S. Geological Survey Open File Report 93-592: 1340 str. Reston, Virginia, USA.

- Clark, R. N., G. A. Swayze, R. Wise, K. E. Livo, T. Hoefen, R. F. Kokaly, S. J. Sutley, 2007: USGS Digital Spectral Library splib06a. U.S. Geological Survey, Digital Data Series 231, https://pubs. er.usgs.gov/publication/ds231.

- Culvenor, D. S., 2002: TIDA: an algorythm for the delineation of tree crowns in high spatial resolution remotely sensed imagery. Computers and Geosciences 28(1): 33-44. Pergamon Press, Inc. Tarrytown, NY, USA

- Diminić, D., N. Potočić, A. Jazbec, M. Županić, 2011: Zaraženost bijelom imelom i status ishrane obične jele u Gorskom kotaru. Croatian Journal of Forest Engineering 32(1): 223-237 str. Zagreb.

- Elvidge, C. D., 1990: Visible and infrared reflectance characteristics of dry plant materials. International Journal of Remote Sensing, vol. 11(10): 1775-1795 str.

- Elvidge, C. D., F. P. Portigal, D. A. Mouat, 1990: Detection of trace quantities of green vegetation in 1989 AVIRIS data. Second Airborne Visible/Infrared Imaging Spectrometer (AVIRIS) Workshop, JPL: 35-41 str. Pasadena, CA.

- Grove, C. I., S. J. Hook, E. D. Paylor, 1992: Laboratory reflectance spectra for 160 minerals 0.4-2.5 micrometers. JPL Publication 92-2.

- Held, A., C. Ticehurst, L. Lymburner, N. Williams, 2003: High resolution mapping of tropical mangrove ecosystems using hyperspectral and radar remote sensing. International Journal of Remote Sensing 24(13): 2739-2759 str.

- Huber, S., M. Kneubühler, N. E. Zimermann, K. Itten, 2005: Potential of Spectral Feature Analysis to Estimate Nitrogen Concentration in Mixed Canopies. 4th Workshop on Imaging Spectroscopy. Warsaw, April 27-29 2005: 1-9 str.

- Idžojtić, M., R. Pernar, Ž. Kauzlarić, M. Abramović, D. Janković, M. Pleše, 2003: Intenzitet zaraze obične jele (Abies alba Mill.) imelom (Viscum album L. ssp. abietis (Wiesb.) Abrom.) na području Uprave šuma podružnice Delnice. Šum. list 11-12, CXXVII: 545-559 str. Zagreb.

- Idžojtić, M., R. Pernar, Z. Lisjak, H. Zdelar, M. Ančić, 2005: Domaćini žute imele (Loranthus europaeus Jacq.) i intenzitet zaraze na području Uprave šuma podružnice Požega. Šum. list 1-2, CXXIX: 3-17 str. Zagreb.

- Idžojtić M., M. Glavaš, M. Zebec, R. Pernar, B. Bradić, D. Husak, 2006a: „Žuta imela (Loranthus europaeus Jacq.) i bijela imela (Viscum album L.) na području Uprave šuma podružnice Bjelovar. Šumarski list. 3-4, CXXX: 101-111 str. Zagreb.

- Idžojtić, M., M. Glavaš, M. Zebec, R. Pernar, P. Beuk, I. Prgić, 2006b: Intenzitet zaraze žutom i bijelom imelom na području Uprava šuma podružnica Vinkovci i Nova Gradiška. Šumarski list, 9-10, CXXX: 399-409 str. Zagreb.

- Idžojtić M., M. Glavaš, M. Zebec, R. Pernar, J. Bećarević, K. Glova, S. Plantak, 2007: Žuta i bijela imela na području uprava šuma podružnica Našice i Osijek. Šumarski list br. 3-4, CXXXI: 125-135 str. Zagreb.

- Idžojtić, M., Z. Marko, 2009: Žuta imela (Loranthus europaeus Jacq.) na hrastu lužnjaku (Quercus robur L.) u Hrvatskoj. U: Matić, S. ; Anić, I. (ur.) Zbornik radova sa znanstvenog skupa Šume hrasta lužnjaka u promijenjenim stanišnim i gospodarskim uvjetima: 117-127 str. HAZU, Zagreb.

- Korb, A. R., P. Dybwad, W. Wadsworth, J. W. Salisbury, 1996: Portable Fourier transform infrared spectroradiometer spectrometer for field measurements of radiance and emissivity. Applied Optics, vol.35, No. 10: 1679-1692 str.

- Kokaly, R. F., R. N. Clark, G. A. Swayze, K. E. Livo, T. M. Hoefen, N. C. Pearson, R. A. Wise, W. M. Benzel, H. A. Lowers, R. L. Driscoll, A. J. Klein, 2017: USGS Spectral Library Version 7: U.S. Geological Survey Data Series 1035: 61 str., https://doi. org/10.3133/ds1035

- Kumar, L., 1998: Modeling forest resources using geographical information system and hyperspectral remote sensing. Unpublished PhD Thesis, University of New South Wales, Sidney.

- Kumar, L., K. Schmidt, S. Dury, A. Skidmore, 2001: Imaging spectrometry and vegetation science. U: van der Meer, F. D., de Jong, S. M. (ur.): Imaging Spectrometry: basic principles and prospective applications, Kluwer Academic Publishers: 111-155 str, Dordrecht, The Netherlands.

- Lucas, R., A. Rowlands, A., O. Niemann, R. Merton, 2004: Hyperspectral Sensors and Applications. U: Varshney, P. K., Arora M. K. (ur): Advanced Image Processing Techniques for Remotely Sensed Hyperspectral Data. Springer-Verlag Berlin Heilderberg New York: 11-49 str.

- Miljković, V., D. Gajski, E. Vela, 2017: Spatial Calibration of the Hyperspectral Line Scanner by the Bundle Block Adjusting Method. Hrvatsko geodetsko društvo, Zagreb, Geodetski list, Vol. 71 (94) No. 2: 127-142 str. Zagreb.

- Pernar, R., M. Bajić, D. Vuletić, M. Idžojtić, M. Ančić, A. Seletković, 2005: Aerial high resolution imaging of the mistletoe for the assessment of forest decline in fir stands. ISPRS Hannover, Commission I, WG I/4.

- Pernar, R., M. Bajić, M. Ančić, A. Seletković, M. Idžojtić, 2007: Detection of mistletoe in digital colour infrared images of infested fir trees. Periodicum Biologorum, vol. 109, No 1, 67-75.

- Piwowar, J. M., D. R. Peddle, D. P. Davidson, 1999: Assessing Annual Forest Ecological Change in Western Canada Using Temporal Mixture Analysis of Regional Scale AVHRR Imagery 
Over a 14 Year Period. Proceedings, 4th Int. Airborne Remote Sensing Conference and Exhibition / 21st Canadian Symposium on Remote Sensing, 21-24 June 1999, Vol. II: 91-97 str, Ottawa Ontario, Canada.

- Rajendran, S., S. Aravindan, T. Jeyavel Rajakumar, R. Sivakumar, K. R. Murali Mohan, 2009: Hyperspectral Remote Sensing and Spectral Signature Applications. NIPA, Pitam Pura, 508 str., New Delhi, India.

- Salisbury, J. W., L. S. Walter, N. Vergo, D. M. D’aria, 1991: Infrared (2.1- 25 micrometers) Spectra of Minerals. Johns Hopkins University Press: 294 str. Baltimore, MD.

- Salisbury, J. W., A. Wald, D. M. D’aria, 1994: Thermal-infrared remote sensing and Kirchhoff's law: 1. Laboratory measurements. Journal of Geophysical Research, vol.99 No. B6: 1189711911 str.

- Santonu, G., M. Kuldeep, 2015: Development of a Web-based Vegetation Spectral Library (VSL) for Remote Sensing Research and Applications. PeerJ PrePrints, CC-BY 4.0 Open Access, https://dx.doi.org/10.7287/peerj.preprints.915v1
- Shippert, P., 2003: Introduction to Hyperspectral Image Analysis. Online Journal of Space Communication, Issue no.3: Remote Sensing of Earth via Satellite: 12 str.

- Šemanjski, S., D. Gajski, M. Bajić, 2009: Transformation of the Hyperspectral Line Scanner into a Strip Imaging System. Proceedings of Disaster Management and Emergency Response in the Mediterranean Region. U: Oluić (ur.). First EARSeL Conference, Zadar, Croatia: 369-375 str.

- Ticehurst, C., L. Lymburner, A. Held, C. Palylyk, D. Martindale, W. Sarosa, S. Phinn, M. Stanforf, 2001: Mapping tree crowns using hyperspectral and high spatial resolution imagery. Proceedings of 3rd International Conference on Geospatial Information in Agriculture and Forestry, Denver, Colorado, CD.

- Treitz, P. M., P. J. Howard, 1999: Hyperspectral remote sensing for estimating biophysical parameters of forest ecosystems. Progress in Physical Geography 23(3): 359-390str.

- Vukelić, J., S. Mikac, D. Baričević, D. Bakšić, R. Rosavec, 2008: Šumska staništa i šumske zajednice u Hrvatskoj, Nacionalna ekološka mreža, Državni zavod za zaštitu prirode, 263 str, Zagreb.

\section{SUMIMARY}

All objects reflect, absorb or emit electromagnetic radiation depending on the composition, creating unique patterns called spectral signatures or endemembers. Pure spectral samples are defined in ideal field or laboratory conditions, where the spectrum of reflection is obtained using a spectroradiometer focused on one surface. According to researches, most spectral-pure samples refer to mineral exploration. Spectral signatures of vegetation, unlike minerals, are dynamic (in spectral, spatial and temporal resolution), considerably demanding for collecting and documenting, and need to be incorporated with caution in spectral libraries. There are several spectral libraries (bigger and smaller) that are organized by chapters which consist of samples that are adequately reviewed and documented to determine the spectrum quality. In this study, the spectral signatures for several species in Croatia were isolated: Oak (Quercus robur L.), Common Beech (Fagus sylvatica L.), Silver fir (Abies alba Mill.), Norway spruce (Picea abies L.), White-berried mistletoe (Viscum album L. ssp. Abietis (Weisb.)) and Yellow Mistletoe (Loranthus europaeus Jacq.). The purpose of the research was to establish a spectral library for future research into hyperspectral scanners for tree species detection.

For collecting spectral signatures, the hyperspectral line scanner ImSpector V9 was used to capture the visible and near infrared spectrum $(430-900 \mathrm{~nm})$. In addition, the FODIS solar radiation sensor was used to obtain the average value of the solar insolation at the time of recording. Recording was performed under controlled conditions. Samples were placed on the circular base with the indicated division for every 45 degrees exactly in the center of the optical axis of the scanner and were rotated circularly. Spectral images were then processed in ImageJ software where data was extracted for further analysis.

After calculation of the mean values by species, comparisons were made between species. The obtained results showed overlaps in the visible part of the spectrum. In the near infrared part of the spectrum they differentiate from one another, apropos the results show that there is a difference between the spectral curves of the samples.

The research carried out defines sampling procedures and obtained spectral signatures for the investigated species. Spectral signatures have become part of the spectral library, and the most significant result of the research is the ability to detect the species on hyperspectral images.

KEY WORDS: spectral signatures (endmembers), pedunculate oak, common beech, silver fir, Norway spruce, white-berried mistletoe, yellow mistletoe. 